\title{
Effect of High Temperature on Mechanical Properties of Geopolymer Mortar
}

\author{
Mateusz Sitarz ${ }^{1}$, Izabela Hager ${ }^{1, *}$, and Joanna Kochanek $^{1}$ \\ ${ }^{1}$ Cracow University of Technology, ul. Warszawska 24, 31-155 Kraków, Poland
}

\begin{abstract}
The advent of modern aluminosilicate binders has resulted in practical uses for fly ash, which belongs to the group of secondary mineral raw materials; this provides an interesting alternative to cementitious binders, which have a large carbon footprint. Geopolymers mineral binders with a growing range of applications in construction. Their inorganic, amorphous structure endows them with better resistance to high temperature compared to cementitious binders. In this study, the alkaline activation of aluminosilicate Połaniec Fly Ash made it possible to obtain noncementitious material with compressive strength of $18.5 \mathrm{MPa}$. The article presents the results of a comparison of characteristics of geopolymer mortar and Portland cement mortar after thermal exposure.
\end{abstract}

\section{Introduction}

Currently, the effects of human interference with the natural environment, the depletion of natural resources, the excessive exploitation of forest resources as well as our impact on the environment through the production of greenhouse gases are becoming increasingly felt. As a result, the idea of sustainable development has gained currency. In the construction industry, this extremely important trend consists in introducing new materials that exhibit a reduced environmental impact and lower energy consumption during their production while maintaining all desirable properties. Researchers are looking for binders consisting mainly of post-process waste that would provide alternatives to cement, and are making efforts to efficiently utilise this type of waste, using it to produce new, safe building materials, which include geopolymers based on active alkali-activated aluminosilicates.

The synthesis of geopolymers enables a significant reduction in greenhouse gas emissions and is a less energy-intensive process compared to the production of traditional cement [1]. Recently, we have seen growing interest in geopolymer binders owing to their favourable mechanical properties and durability, low cost of manufacturing and high resistance to chemical agents as well as to high temperature [1-3]. Thanks to these properties, geopolymer materials may provide an interesting alternative to traditional cementitious binders.

\footnotetext{
*Corresponding author: ihager@pk.edu.pl
} 


\section{Effect of temperature on cementitious and geopolymer binders}

It is known from literature that changes in the properties of heated mineral composites with cementitious binders depend on the composition and type of the aggregate used, the watercement ratio as well as the content of pozzolanic additions. The rate at which the element is heated is an important factor as well. As the temperature rises, the water gradually evaporates, the C-S-H phase becomes dehydrated and portlandite decomposes [4].

During the heating of concrete, the volume of aggregate increases and the cementitious binder shrinks, which results in a significant loss in material strength [4]. A similar mechanism was observed in the case of geopolymers. Differences in coefficients of thermal expansion between aggregate and cement paste cause damage to composites under elevated temperature conditions. The extent of damage depends on the coefficient of thermal expansion of the aggregate used and on the properties of the cement paste such as the amount of shrinkage and its ability to absorb the resulting strains $[5,6]$.

Tests of temperature effects carried out by various teams have confirmed the geopolymers' robust resistance to high temperature. Davidovits [7] demonstrated that properly designed geopolymer binders can exhibit fire resistance up to $1200^{\circ} \mathrm{C}$. Barbosa and Mackenzie [8] analysed the behaviour of a metakaolin geopolymer with an activator that contained sodium silicate and sodium hydroxide. At $100-200^{\circ} \mathrm{C}$, the material shrank only slightly due to water loss. In the $250-800^{\circ} \mathrm{C}$ range, the specimens maintained dimensional stability. At $800^{\circ} \mathrm{C}$, shrinkage was observed due to increasing density and changes in volume caused by the crystallisation of new phases. At temperature ranging from $880^{\circ} \mathrm{C}$ to $900^{\circ} \mathrm{C}$, this process was halted and the specimens maintained dimensional stability (depending on differences in their composition) up to $1000-1300^{\circ} \mathrm{C}$, and after that they eventually melted. When Bakharev [9] investigated fly ash-based geopolymer with an activator containing $\mathrm{Na}$, she observed shrinkage cracks and a sudden decrease in strength at $800^{\circ} \mathrm{C}$.

According to many researchers [6,10-14] dimensional stability and the geopolymer's resistance to high temperature depend on binder composition, including without limitation the $\mathrm{Si} / \mathrm{Al}$ ratio, alkali content and the liquid/solid relationship. Alkali content has a dual effect. On the one hand, high alkaline substance content accelerates the activation reaction and makes it possible to obtain a material with high initial strength. On the other hand, alkali content must be limited in order to ensure the thermal stability of the material. A high alkali content in a composite which is exposed to high temperature accelerates the melting of the material. Another important factor is the $\mathrm{SiO}_{2} / \mathrm{Al}_{2} \mathrm{O}_{3}$ ratio. The most desirable ratio ranges from 2 to 4 - within this range, the initial strength of the material increases and thermostable zeolites are formed. Higher ratios hinder the formation of these structures and promote sintering. At lower ratios, excessive formation of zeolites may occur at high temperature, increasing internal strain in the material. In their work concerning the effect on elevated temperature on cement paste, mortar and light geopolymer concrete, Abdulkareem et al. [15] noted that materials with highest amounts of activator solution exhibited the largest decrease in strength when heated to 400,600 and $800^{\circ} \mathrm{C}$.

Fan et al. [16] analysed the impact of the water/ash ratio on the strength of a geopolymer made from class $\mathrm{F}$ fly ash, $\mathrm{KOH}$ and $\mathrm{Na}_{2} \mathrm{SiO}_{3}$. On the basis of the tests conducted, it was found that the optimal water-to-ash ratio was 0.3 . At this ratio, the highest residual strength after heating to $500^{\circ} \mathrm{C}$ was observed. In addition, no spalling was observed during the tests. The authors indicated that differences in coefficients of thermal expansion between the matrix and the aggregate were the main reason for the loss in geopolymer concrete strength under high temperature conditions [17,18]. 


\section{Experimental details}

Twelve specimens in the form of 40x40x160mm beams were made from each tested mortar. Cement mortar specimens were marked $\mathrm{H} 1$ to $\mathrm{H} 12$ and geopolymer mortar specimens were marked G1 to G12. After demoulding, cement mortar specimens were first cured in water for 7 days and subsequently under air-dry conditions until the tests were conducted. After forming, geopolymer mortar specimens were kept at $70^{\circ} \mathrm{C}$ for 24 hours and then cured for 27 days under air-dry conditions.

In this investigation siliceous fly ash from Połaniec power station was used as source material to prepare the geopolymer mortar. Total content of silicon dioxide, alumina and iron (III) oxide exceeds $70 \%$, loss of ignition at around 5\%. The fractions $0-15 \mu \mathrm{m}$ and $15-30 \mu \mathrm{m}$ represent almost half of the composition of the fly ash. The activating alkali liquids consisted of $\mathrm{Na}_{2} \mathrm{SiO}_{3}$ and $\mathrm{NaOH}$ beads. $\mathrm{Na}_{2} \mathrm{SiO}_{3}$ solution had a modulus ratio (Ms) equal to 2.5 where $\mathrm{Ms}=\mathrm{SiO}_{2} / \mathrm{Na}_{2} \mathrm{O}, \mathrm{Na}_{2} \mathrm{O}=11.1 \%, \mathrm{SiO}_{2}=27.9 \%$ and water- $61.0 \%$. The $\mathrm{NaOH}$ beads and $\mathrm{Na}_{2} \mathrm{SiO}_{3}$ solution were mixed together with $\mathrm{Na}_{2} \mathrm{SiO}_{3} / \mathrm{NaOH}$ mass ratio of 3. Composition of tested materials is given in Table 1

Table 1. Composition of cement and geopolymer mortar.

\begin{tabular}{|l|c|c|c|c|}
\hline \multirow{2}{*}{ Component } & \multicolumn{2}{|c|}{ Cement mortar } & \multicolumn{2}{c|}{ Geopolymer mortar } \\
\cline { 2 - 5 } & Mass [g] & Vol. $/ 1 \mathrm{~m}^{3}$ & Mass [g] & Vol./1 $\mathrm{m}^{3}$ \\
\hline Ożarów CEM I 32.5R cement & 450.0 & 0.167 & - & - \\
\hline Sand 0-2 mm & 1350.0 & 0.578 & 1350.0 & 0.367 \\
\hline Water & 225.0 & 0.225 & 150.0 & 0.108 \\
\hline Sodium silicate & - & - & 337.5 & 0.165 \\
\hline Sodium hydroxide & - & - & 112.5 & 0.038 \\
\hline Połaniec fly ash & - & - & 800.0 & 0.303 \\
\hline Plasticiser & - & - & 30.0 & 0.019 \\
\hline
\end{tabular}

The purpose of the conducted research was to compare the strength characteristics (flexural tensile strength and compressive strength) of standard Portland cement mortar and of mortar based on geopolymer binder after heating specimens in a furnace at a rate of $1{ }^{\circ} \mathrm{C} / \mathrm{min}$ to $200,400,600$ and $800^{\circ} \mathrm{C}$ and then cooling them down to room temperature. All tests were conducted after 28 days of curing. Compressive strength tests were carried out on the specimens remaining after flexural strength tests. Three specimens were tested for each heating temperature.

\section{Results and discussion}

After the specimens reached 28-day, their bulk densities and strength characteristics were tested at $20^{\circ} \mathrm{C}$. The following results were obtained for geopolymer $\mathrm{G}$ and cement mortars $(\mathrm{H})$ : average density $\rho_{\mathrm{OG}}=1.77 \mathrm{~g} / \mathrm{cm}^{3}, \rho_{\mathrm{oH}}=2.23 \mathrm{~g} / \mathrm{cm}^{3}$, average flexural strength $\mathrm{f}_{\mathrm{tG}}=5,00 \mathrm{MPa}$, $\mathrm{f}_{\mathrm{tH}}=8.07 \mathrm{MPa}$ and compressive strength $\mathrm{f}_{\mathrm{cG}}=20.14 \mathrm{MPa}, \mathrm{f}_{\mathrm{cH}}=52.05 \mathrm{MPa}$. Analogous analysis was repeated for specimens subjected to heating to $200^{\circ} \mathrm{C}, 400^{\circ} \mathrm{C}, 600^{\circ} \mathrm{C}$ and $800^{\circ} \mathrm{C}$ and subsequently cooled to room temperature. 

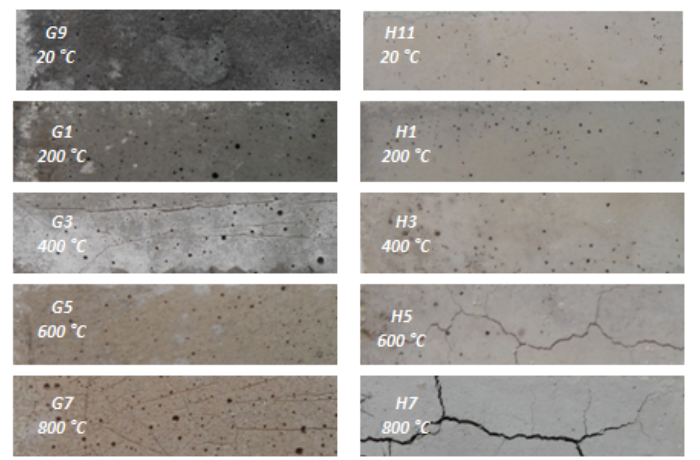

Fig. 1. Mortar specimens aspect after heating: geopolymer (left) and cement (right)

Fig. 1 presents the appearance of specimens after heating. Clear differences can be noticed in the thermal resistance of the materials compared. On cement mortar specimens, there are visible cracks which emerged at $600^{\circ} \mathrm{C}$.

Based on the visual inspection of specimens, the geopolymer mortar exhibited significantly better thermal resistance. On the photographs below, changes in the colour of mortars based on geopolymer and cementitious binders as a result of heating are shown. The photographs show specimen cross-sections after flexural strength tests.

a)

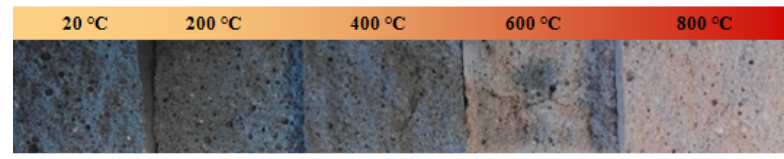

b)

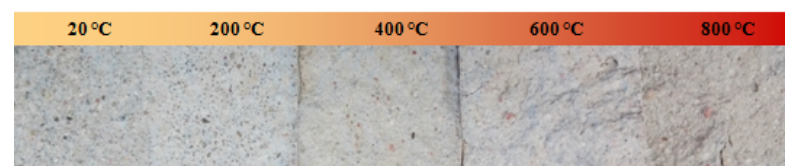

Fig. 2. Colour change of heated mortars: a) geopolymer; b) cement

The chart below presents changes in the bulk density of the materials tested; relative values are compared, i.e. the ratio of the density of the heated specimen to the density of a specimen which was not subjected to high temperature.

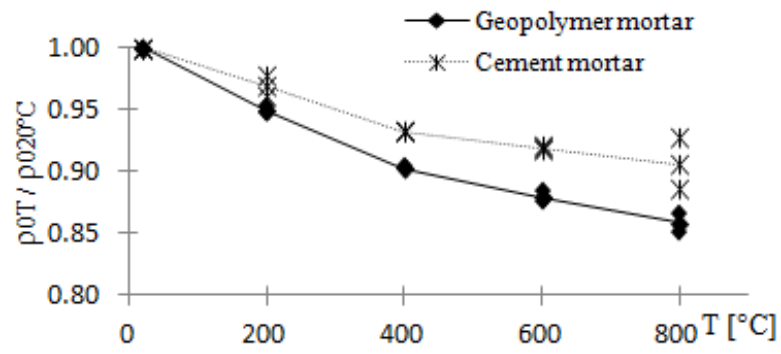

Fig. 3. Relative density of heated geopolymer and cement mortar specimens.

The chart shows that both materials exhibit a decrease in density with the increase of temperature, which results mainly from loss of water. After analysing the weight loss of the materials analysed, it can be concluded that geopolymer mortar specimens showed greater weight loss.

In order to determine changes in mechanical properties under high temperature conditions and to compare the thermal resistance of geopolymer mortar and cement mortar, flexural 
strength and compressive strength tests were conducted both on unheated specimens and on specimens exposed to temperature of $200^{\circ} \mathrm{C}, 400^{\circ} \mathrm{C}, 600^{\circ} \mathrm{C}$ and $800^{\circ} \mathrm{C}$. Strength tests on specimens were conducted after 28 days, in each case for two unheated specimens and two specimens exposed to high temperature. The charts in Fig. 4 present a comparison of the relative flexural and compressive strength of the materials tested, i.e. the ratio of the strength of the heated specimen to the strength of the specimen not exposed to high temperature.

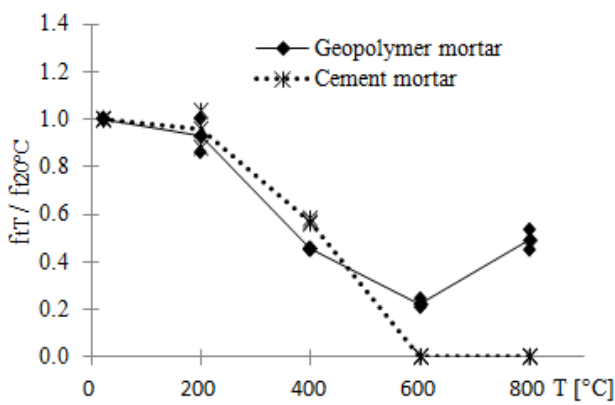

a)

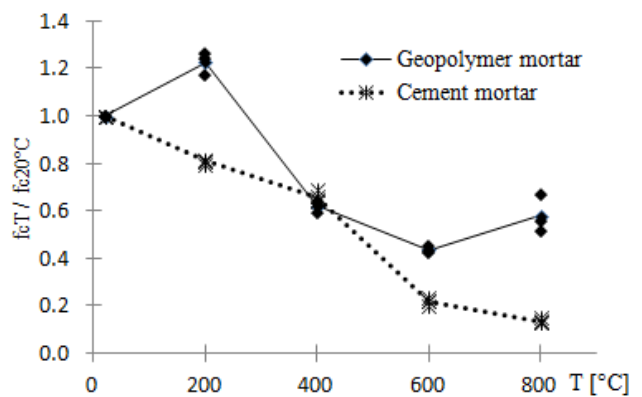

b)

Fig. 4. Changes in relative values of a) flexural and b) compressive strength as a result of heating

As a result of exposure to high temperature, the mechanical properties of both materials deteriorate gradually. Flexural tensile strength decreases by approximately $7 \%$ for both materials; after heating to $400^{\circ} \mathrm{C}$, the decrease already amounts to $43 \%$ and $55 \%$ for geopolymer and cement mortar, respectively. After heating to $600^{\circ} \mathrm{C}$, cement mortar strength drops to zero, which is the result of the visible cracking of the specimen, the dehydration of cement paste and the decomposition of portlandite. The tensile strength of geopolymer mortar heated to the same temperature is still at $20 \%$ of the initial value. Interestingly, heating to $800^{\circ} \mathrm{C}$ results in a slight increase in strength.

The compressive strength of cement mortar as a result of heating exhibited a quasi-linear decrease within the entire tested temperature range, which was the result of the $\mathrm{C}-\mathrm{S}-\mathrm{H}$ phase dehydration process, portlandite decomposition and the cracking, which was clearly visible on the surface of the specimens heated to $600^{\circ} \mathrm{C}$ and $800^{\circ} \mathrm{C}$.

In the case of the geopolymer mortar, an increase in compressive strength was observed at $200^{\circ} \mathrm{C}$. This increase is most probably caused by the progressive geopolymerisation process, which results in the strength increase of the material. Further geopolymer heating to $400^{\circ} \mathrm{C}$ and $600^{\circ} \mathrm{C}$ caused a progressive decrease in strength by $38 \%$ and $58 \%$, respectively, compared to the initial value recorded at $20^{\circ} \mathrm{C}$. On the other hand, after the material had been heated to $800^{\circ} \mathrm{C}$, an increase in strength was observed again, probably resulting from the sintering of mineral ingredients.

\section{Conclusion}

The resistance of mineral composites to high temperature depends on many factors. In geopolymer mortars, just as in cement mortars, the paste becomes dehydrated and shrinks while aggregate volume increases. However, the number and size of the cracks visible to the naked eye in cement mortar after heating to $600^{\circ} \mathrm{C}$ and $800^{\circ} \mathrm{C}$ are significantly greater than in geopolymer mortar.

The compressive strength of geopolymer mortars increases after heating to $200^{\circ} \mathrm{C}$, reaching $123 \%$ of the initial value, which is most probably the result of the continued polymerisation process. Heating to $400^{\circ} \mathrm{C}$ and $600^{\circ} \mathrm{C}$ results in compressive strength decreasing by $38 \%$ and $58 \%$, respectively, relative to the initial values recorded at $20^{\circ} \mathrm{C}$. At 
$800^{\circ} \mathrm{C}$, the material in fact becomes stronger as a result of the sintering of the sodiumaluminosilicate phase, which yields an increase of strength.

As concerns the appearance of specimens after heating, geopolymer materials exhibit greater resistance to high temperature. Despite their lower initial strength values, the geopolymer mortars tested showed greater absolute strength after being heated to $600^{\circ} \mathrm{C}$ and $800^{\circ} \mathrm{C}$ compared to cement mortars.

The research conducted has demonstrated that geopolymers exhibit better thermal resistance than cement mortar, which loses its mechanical properties when heated to a temperature higher than that at which portlandite decomposes. An interesting phenomenon which requires further research is the behaviour of geopolymer binders at temperature higher than $800^{\circ} \mathrm{C}$.

\section{References}

1. L. Provis, J.S.J. Van Deventer, Geopolymers: structure, processing, properties and industrial applications (Woodhead Publishing, Cambridge, 2009)

2. P. Duxon, A. Fernandez-Jiminez, JL. Provis, GC. Luckey, A. Palomo, J.S.J. Van Deventure, J. Mater. Sci. 42, 2917-2933 (2007)

3. C. Li, H. Sun, L. Li, Cem. Concr. Res. 40, 1341-9 (2010)

4. I. Hager, Bull. of the Pol. Academy of Sci. Tech. Sci. 61, 145-154 (2013)

5. S. Subaer, A. van Riessen, J. Mater. Sci. 42, 3117-3123 (2006)

6. D.L.Y. Kong, J.G. Sanjayan,, Cem. Concr. Compos. 30, 986-991 (2008)

7. J. Davidovits, Geopolymer, chemistry and applications (Institut geopolimere, SaintQuentin, 2011)

8. V.F.F. Barbosa, K.J.D. Mackenzie, Mater. Res. Bull. 38, 319-331 (2003)

9. T. Bakharev, Cem. Concr. Res. 36, 1134-1147, (2006)

10. A. Fernández-Jiménez, J.Y. Pastor, A. Martín, A. Palomo, J. Am. Ceram. Soc. 93, 3417-3417 (2010)

11. J. Ye, W. Zhang, D. Shi, Constr. Build. Mater. 69, 41-48 (2014)

12. P.V. Krivenko, G.Y. Kovalchuk, J. Mater. Sci. 42, 2944-2952 (2007)

13. D.L.Y. Kong, J.G. Sanjayan, K. Sagoe-Crentsil, Cem. Concr. Res. 37, 1583-1589 (2007)

14. J. Temuujin, W. Rickard, A. van Riessen, Adv. Powder. Technol. 24, 495-498 (2013)

15. O. A. Abdulkareem et al., Constr. Build. Mater. 50, 377-387 (2014)

16. F. Fan et al., Constr. Build. Mater. 160, 66-81 (2018)

17. D.L.Y. Kong, J.G. Sanjayan, Cem. Conc. Res. 40, 334-339 (2010)

18. W.D.A. Rickard, G.J.G. Gluth, K. Pistol, Cem. Concr. Res. 80, 33-43 (2016) 